\title{
GIS Based Tsunami Risk Assessment in Weligma, Sri Lanka
}

\author{
W.A.A.P Wijesundara \\ National Aquatic Resources Research and Development Agency (NARA) \\ *Corresponding Author: Wpanu12@gmail.com
}

Copyright (C) 2014 Horizon Research Publishing All rights reserved.

\begin{abstract}
A tsunami is a natural coastal hazard generated in the deep ocean as a result of an earthquake, volcanic activity, submarine landslide or meteoritic impact. The 26th Dec. 2004 earthquake off the west coast of Sumatra, Indonesia generated one of the deadliest tsunami in history. It demolished the coastal areas of Indonesia, Sri Lanka, India, and Thailand, as these countries located shadow zone of this tectonic belt. Over thirty thousand loss their lives and also millions of worth extensive property damaged. As Sri Lanka situated in a shadow zone of the earthquake generated belt preparedness is very important factor. The study focused towards creation of a Tsunami risk map for Weligama area. The numerical simulation of tsunami inundation was carried out using ComMIT model with the major input parameters of earthquake source parameters, topography and bathymetry data. The December 2004 Sumatra Earthquake source parameters were used for generation, propagation, and coastal amplification of the tsunami waves and finally the inundation extent and water level was obtained to prepare large scale action maps on tsunami inundation to protect the coastal communities. The GIS tool has been used to incorporate the tsunami inundation depth to prepare the final tsunami risk map. Reliability of model results was compared with the field data and a high resolution QuickBird images with pre and post tsunami. The results from this study will be useful for long - term planning in vulnerable coastal communities and providing early warnings to take precautions to reduce impacts of tsunami in future.
\end{abstract}

Keywords Tsunami Inundation, Numerical Simulation, Early Warning, Pre and Post Tsunami, Coastal Communities

\section{Introduction}

Tsunami is a series of large waves of extremely long wavelength and period usually generated by a violent, impulsive undersea disturbance or activity near the coast or in the ocean (Ramy, 2005). In the deep sea, it is propagate with high speed and the low wave amplitude. At the same time wave amplitude is rapidly increasing and converts in to killer waves and inundates low-lying coastal areas resulting mass destruction. When the tsunami waves reach shore, speed of the waves decrease according to the topography of the sea bed. Tsunami waves are mainly formed with the sudden displacement of seabed due to an underwater earthquake. In the deep sea, it propagates with a high speed and low wave amplitude. When the tsunami waves reach the shore, the speed of the waves decreases according to the topography of the seabed. At the same time, the wave amplitude increases rapidly and converts into killer waves and inundates low-lying coastal areas, resulting in mass destruction.

In order to reduce the impact of tsunamis, it is beneficial to have a thorough understanding of the area at risk, its population, infrastructure, and pattern of land use. In order to reduce the impact of tsunamis, it is beneficial to have a thorough understanding of the area at risk, its population, infrastructure, and pattern of land use. Early warning and evacuations based on inundation maps are the most strategic ways to minimize massive loss of life and damages to the property in risk community \& most countries now start to prepare disaster prevention plans. Therefore it is important to prepare large scale action maps on tsunami inundation incorporating land use details using a GIS tool. Hazard assessment studies integrated with inundation information allows determining level of vulnerably associated with coastal belt. Risk assessment process requires the use of mathematical models to simulate the generation, the propagation across the ocean, and eventually, the inundation for historical or hypothetical source.

\subsection{Background of the Study}

Tsunamis are a major concern to the Pacific islands and Asian coastal nations because they may occur at any time, with little or no warning, and with destructive force. During the past decade, more people have died from tsunamis than from hurricanes, earthquakes, and floods combined. A tsunami is caused when there is a disturbance deep under the ocean such as an earthquake, volcano or a landslide. An underwater earthquake is the most common cause for a tsunami, but not just any underwater earthquake causes a 
tsunami. The earthquake needs to be a large enough earthquake of around 7.0 magnitudes or bigger.

Sri Lanka experienced its worst natural disaster on the 26th Dec. 2004 one of the hardest hit countries in terms of loss of life, infrastructure and assets. Current estimates stand at more than 31000 lives lost, over 4000 missing and 1 million affected. These are staggering numbers for any country, but especially for Sri Lanka when they are compared in relative terms and the capacity to recover (Herath, 2008). The reconstruction should take place based on an assessment of risks and appropriate measures to minimize losses from a future similar disaster. Although the frequency of Tsunami in Sri Lanka is very small, should avoid rebuilding the same disaster. To assess risks, accurate representation of topography when inundation impacts on people are considered. Therefore it is necessary to step up tsunami awareness effects such as tsunami forecasting methods and inundation maps at risk communities in Sri Lanka. Properly prepare against the threat of tsunami inundation, thus saving lives and protecting property. It is helpful for risk analysis process with population density and Land use information \& Disaster management activities.

\subsection{Statement of the Problem}

Any natural Hazard results to a disaster depending upon its magnitude of the impact. Natural hazard such as an undersea earthquake may cause a Tsunami hazard to the coastal land region resulting in a disaster, damaging property and people. Since such type of natural hazards cannot be controlled, they can be monitored and precautionary/safety planning can be done along the coastal regions to safeguard from the damages. The assessment of Tsunami impact over the people and property was important for planning the relief actions. Hence the requirement for the Tsunami Disaster Mapping to identify the Tsunami affected for planning purpose is the essential exercises for managing future.

\subsection{Justification of the Study}

The tsunami impact study is undertaken along coastal belt of Weligama area, which is located at latitude $05^{\circ} 51^{\prime} 14.697^{\prime}$ $\mathrm{N}-05^{\circ} 58^{\prime} 6.541^{\prime \prime} \mathrm{N}$ and longitude $80^{\circ} 34^{\prime} 57.477^{\prime \prime} \mathrm{E}$ to $80^{\circ}$ 22 ' 7.139" E respectively. The study area was badly hit by tsunami waves and is highly affected to the fisheries sector as there is a major fishery harbour called Mirissa located close to the bay of Weligama. The tsunami resulted in major, but great damages to the Weligama area infrastructure $\&$ assets and lost massive of lives. Under tsunami inundation mapping along Weligama coast an integrated approach is adopted to identify the vulnerable areas.

The main objective of this study is to integrate a tsunami simulation model and remote sensing data with the available topographic data using a GIS tool for Tsunami inundation mapping and risk mapping to identify the disaster risk to provide facility for decision makers to understand an evacuation planning $\&$ in public education \& awareness activities.

\subsection{Literature Review}

Inundation maps are depictions of coastal areas that identify regions, populations, and facilities that are at risk from tsunami attack, which could be used by emergency planners for disaster response and mitigation. Inundation maps require an assessment of local and far-field geologic hazards, and the calculation of coastal flooding (Kumar, 2008). Numerical simulations are useful tools for analyzing tsunami propagation, coastal amplification and inundation (Alpar et al, 2006). The tsunami inundation hazard map of the study area is based on numerical simulation of waves generated by a scenario earthquake. The earthquake scenario adopted for the study was December 2004 Sumatra earthquake responsible for major devastation in the study area. The numerical simulation of tsunami inundation was carried out using TUNAMI N2 model. The major input parameters for the model were earthquake source parameters, topography and bathymetry data. The December 2004 Sumatra Earthquake source parameters were used for generation, propagation, and coastal amplification of the tsunami waves and finally the inundation extent and depth were obtained for Galle city (Borah, 2007). The model used is the Tsunami N2 model of Fumihiko Imamura (IUGG/IOC Time Project, 1997). The shallow water wave equations are governing equations behind the model. It uses a nested grid of topographic and bathymetric elevations and calculates a wave elevation and velocity at each grid point at specified time intervals to simulate the generation from Sumatra source, propagation through Ocean and finally inundation at land (Imamura, 1995).

The tsunami itself was generated along the $1200 \mathrm{~km}$ fault rupture and the waves were recorded over $5000 \mathrm{~m}$. Much research has been carried out to determine the impact of tsunamis on coastal environments such as the nature of inundation, runup level, erosion, deposition, vegetation, etc. in damaging the coast. Tsunami flooding or the volume of water carried onshore is directly related with the size of tsunami and its wave period. The limit of landward incursion is the maximum distance that run-up can penetrate inland and can be given the following formula; by computer methods. The last step was accomplished chiefly by prior conclusions about inland penetration;

$$
\mathrm{X} \max =(\mathrm{Hs}) 1.33 \mathrm{n}-2 \mathrm{k}(1)
$$

Where $\mathrm{k}$ is a constant and taken as 0.06 for many tsunamis.

$\mathrm{n}$ - is another constant and depends on the characteristics of the inundation area. It is 0.015 for smooth terrains such as grasslands or tidal plains, 0.03 for areas covered in buildings and 0.07 for landscapes densely covered with forest.

A tsunami $2.6 \mathrm{~m}$ high can penetrate $950 \mathrm{~m}$ inland for smooth plains. However, since the study area is a developed land on flat coastal plains, such a tsunami can only penetrate $250 \mathrm{~m}$ inland. Mapping Tsunami Inundation, inundation limit for a Digital Terrain Model (DTM) with a vertical resolution of $\pm 1.2 \mathrm{~m}$ was used (Alpar et al, 2006). To establish a cost effective method and a quick determination 
of factors that influence damage intensity in tsunami prone areas, one must analyze the preparatory or causal controlling factors using remote sensing and GIS methodology. For a better understanding of the complex Processes and their interactions during tsunami inundations, emphasis is put on a spatially accurate, GIS integrated representation of those influencing parameters and determining factors - provided that such data is available. A systematic GIS approach is recommended for tsunami risk site detection based on SRTM data extracting geomorphometric as part of a Tsunami / Hazard Information System. The evaluation of digital topographic data is of great importance as it contributes to the detection of the specific geomorphologic/ topographic settings of tsunami prone areas. Hazard assessment study is necessary to understand the above mention contributing factors influence in tsunami height and inundation extent spatial variation along coastal belt Such studies (Willige, 2006). Tsunami intensity scale considers inundation depth as one of the vital parameter for quantification of level of damage caused by tsunami (Imamura, 2001). These depth ranges were chosen for hazard analysis because they are approximately knee-high or less, knee-high to head-high, and more than head-high (Timothy et al. 2004).

\subsection{Study Area}

The tsunami impact study is undertaken along the coastal belt of Weligama area, which is approximately $35 \mathrm{~km}$ long including the Weligama bay in the South coast of Sri Lanka (Figure 1). This area was badly hit by the 2004 December tsunami waves and is currently involved in large development reconstructions activities.

\subsection{Data and Materials Used}

- Topographic Data

- LiDAR ( Light Detection And Ranging)

- Contour Maps (1:10,000 \& 1: 50, 000)

( Source: Survey Department of Sri Lanka)

- Bathymetry Data

- Echo sounder data ( From National Hydrographic Office/ NARA)

1. Coast Line

2. Off shore bathy and near

shore bathy data

- Nautical charts - Published by

NHO/NARA \& Admiralty Charts - UKHO

(Source: United Kingdom Hydrographic Office)

- GEBCO (General Bathymetric Charts

of the Ocean) 30 sec. data (Source: www.gebco.net)

- $\quad$ Satellite data

- Quick Bird Image (2007)

- Vector Data

- Land Use

- Raster Data

- SRTM DEM

- Demographic Data

- Census data from Census \& Statistics

Department of Sri Lanka

Data can be analyzed and processed by using the following software's :

- ComMIT Numerical Model - To identify the tsunami propagation and inundation

- ArcGIS 9.3, ERDAS Imagine 9.2, Global Mapper, Surfer 8 - To prepare the final outputs

- $\quad$ Hypack Gold 4.3,PDS 2000, CARIS GIS 4.4, Auto CAD 2007, 2008- Process the bathy and topographic data

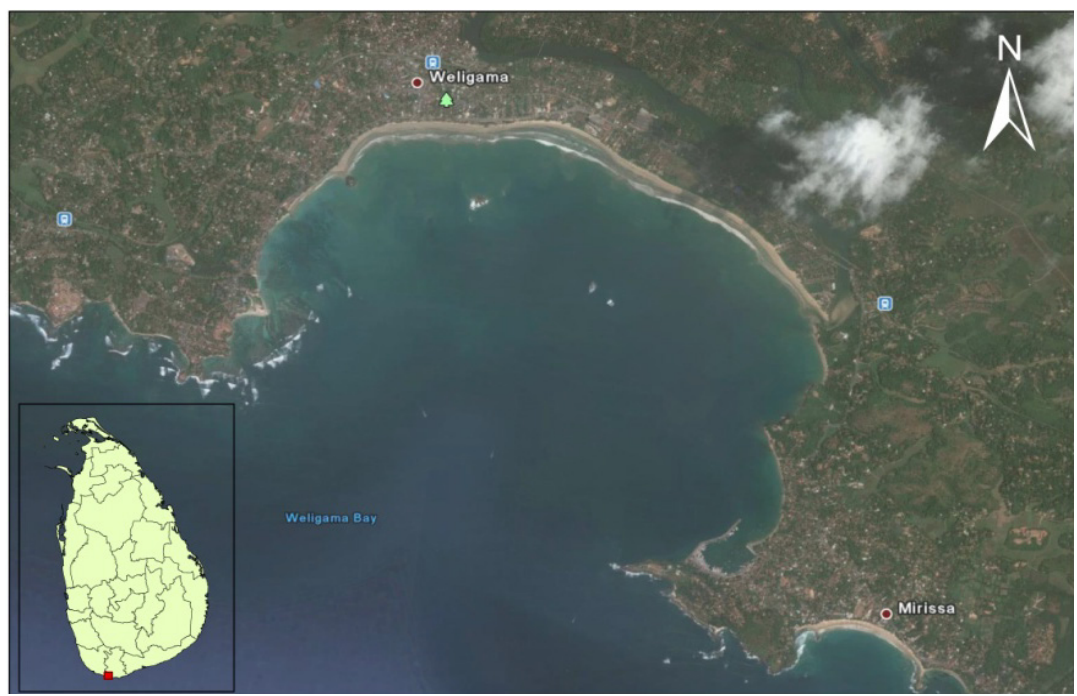

Figure 1. Weligama Coastal Region 


\section{Methodology}

\subsection{Data Preparation}

The run-up of the tsunami on to land is the most undeveloped part of the tsunami model, primarily because of the lack of the two major types of data i.e the high quality field measurements for testing of the models and fine resolution bathymetric \& topographic data (Titov, 1997). Hence, in this study, all available local and global bathymetric data, topographic data and Lidar data were brought into the world geodetic coordinate system (WGS 84) and merged together to generate the Digital Terrain Model (DTM). By using Krigging method, data was interpolated for creation the three nested grids with both bathymetric and topographic data. Using DTM, all undesirable elevations and depths were removed and converted into ASCII grid format for propagation and the Tsunami numerical modelling to study tsunami inundation, maximum wave height, wave speed, and reflection in the Weligama coastal area. (Figure 2)

Accurate bathymetric data of shallow water with digital topographic data and LIDAR data was prepared in the selected study area by using ARCGIS software which can be used to generate the tsunami wave by using ComMIT simulations model. Accurate bathymetric data of shallow water and GEBCO (1 min.) bathymetry data with digital topographic data and LIDAR data merged and use for propagation and inundation modelling to study tsunami inundation \& maximum wave height in the Weligama. By using Krigging method, data was interpolated with Surfer software for creation the three nested grids with both bathymetric and topographic data. Global Mapper software used to convert three nested grids into Geo Tiff (Raster) format and with ArcGIS software convert consecutive grids into ASCII format which is support for physical modelling to incorporate and analyse the maximum wave run-up.

The three nested grids data in ASCII format used to propagation and run the ComMIT numerical model according to inundation distance and maximum wave height to study tsunami inundation, maximum wave height, wave speed, and reflection in the Weligama costal area. ComMIT model was run mainly based on the earthquake off the west coast of Sumatra, Indonesia in December, 2004. The earthquake scenario was considered as 9.3 which was marked as the value in Richter magnitude and slip was limited to $20 \mathrm{~m}$ and fault length was measured as $1100 \mathrm{~km}$ from the location which was generated earthquake to the study area. The numerical model was run according to these parameters to observe inundate areas with maximum wave heights.

\subsection{Tsunami Numerical Modeling}

The ComMIT Numerical model was used for identifying the tsunami propagation, coastal amplification and inundation. The model was developed by Vasli Titov at the NOAA center for tsunami research, based on non-linear shallow water equations and governing equations. A magnitude of 9.2 on the Rictour scale and $1200 \mathrm{~km}$ length of fault rupture were used as parameters of the earthquake scenario that was relevant to the 2004 Sumatra earthquake. It uses a three-nested grid of bathymetry and topography. A combination of high-resolution bathymetric and topographic data was used for the inner grid, which covers the entire study area while GEBCO and SRTM data were used for the other two grids. Models calculated the velocity at each grid point at specified time intervals to simulate the generation from the Sumatra source, propagation through the Ocean and finally, inundation at land (Imamura et al., 1995).

\subsection{Inundation Map, Hazard Map and Risk Map Creation}

The GIS environment has been used to incorporate and analyse the maximum wave run-up. According to the results, maximum wave run up "NetCDF" raster file used to prepare the inundation map of the study area. The computed inundation depth is classified into four ranges for quantification of level of hazard damages. The physical characteristics of the coastal area (land use and population) and the built environment in the area considered to determine the vulnerability. A risk to a natural event is defined as the mathematical product between vulnerability and hazard; it refers to the expected loss from a given hazard to a given element at risk. 


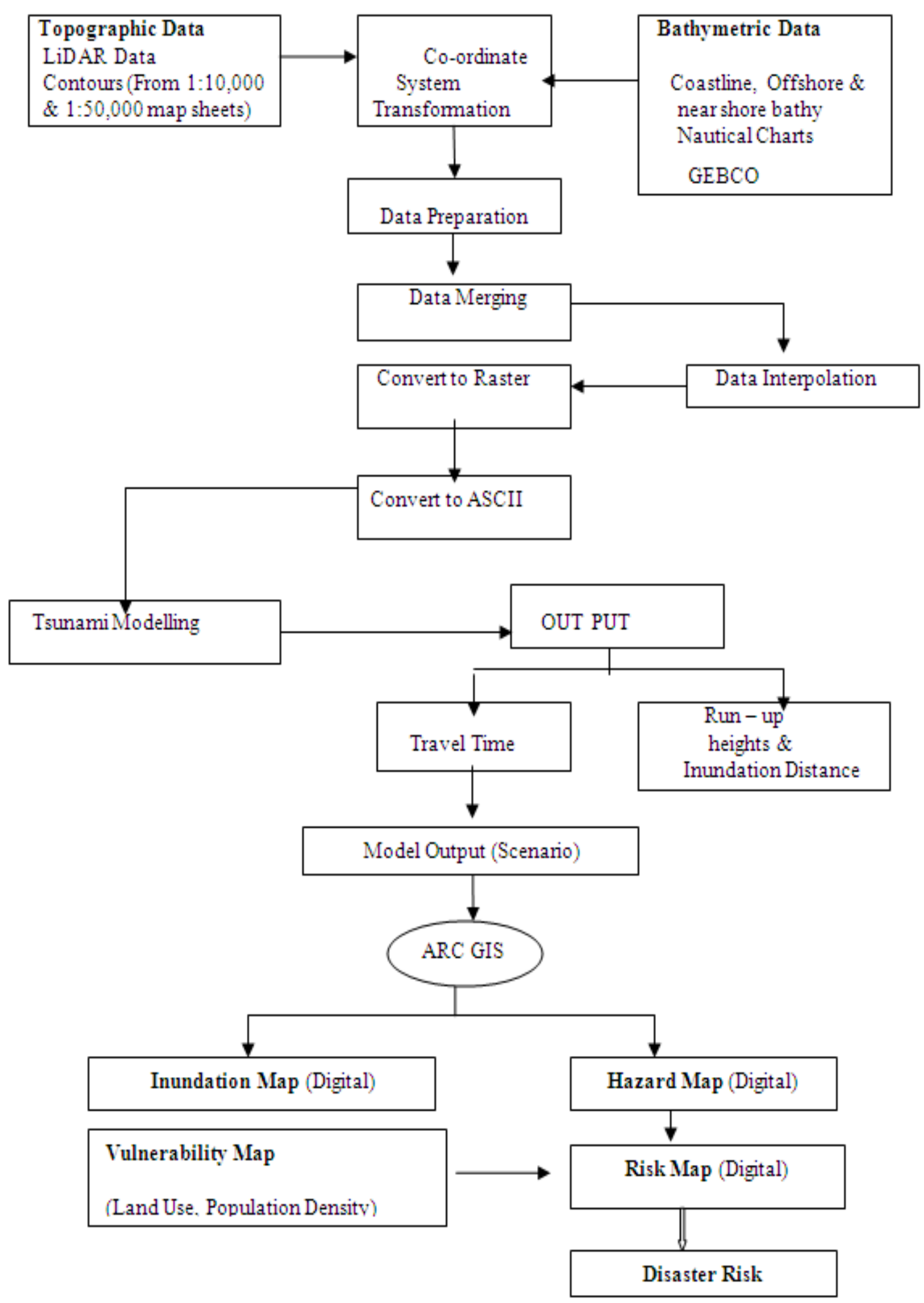

Figure 2. Flow diagram of the methodology 


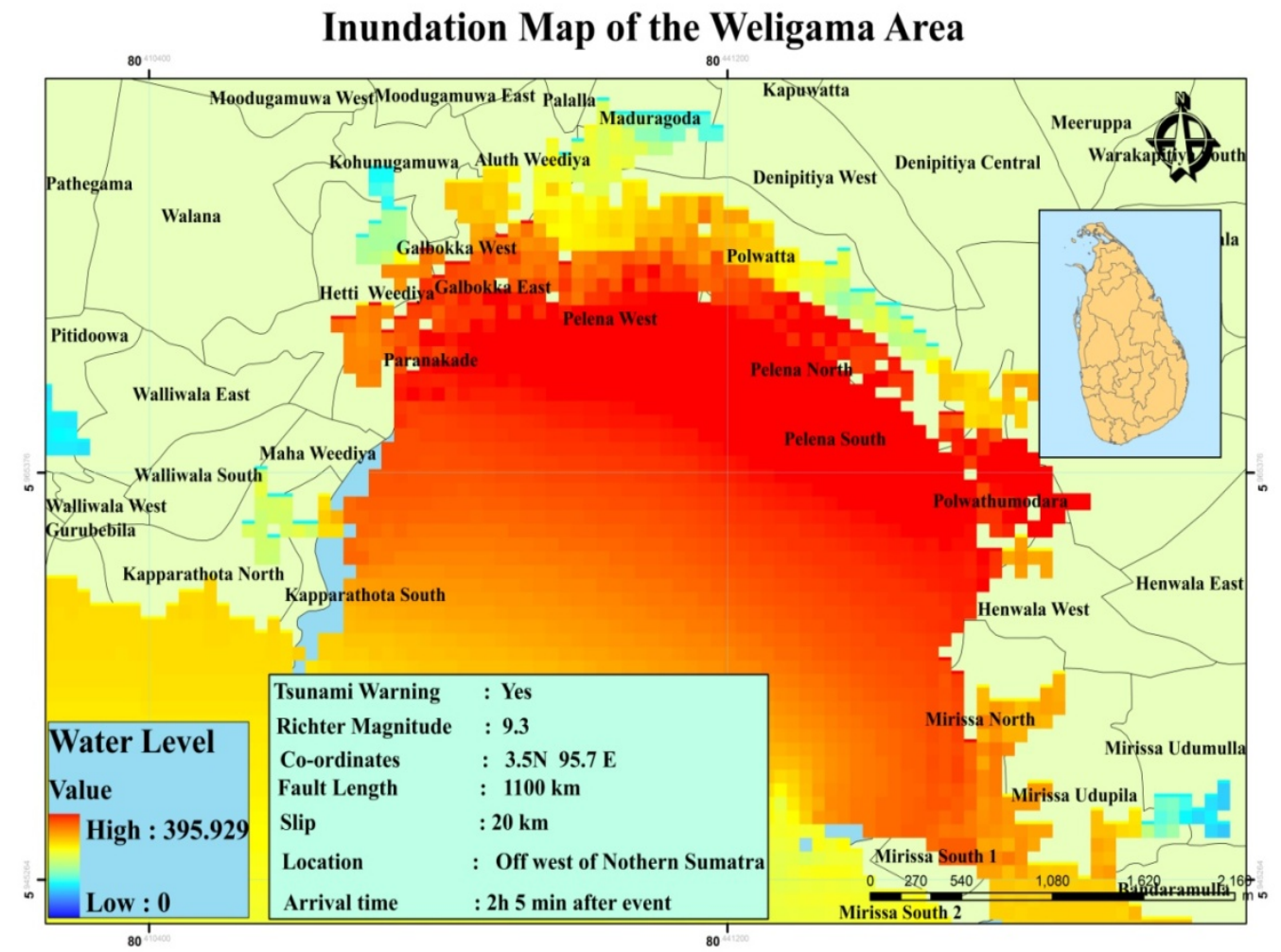

Figure 3. Inundation Depth distribution in Weligama Bay area

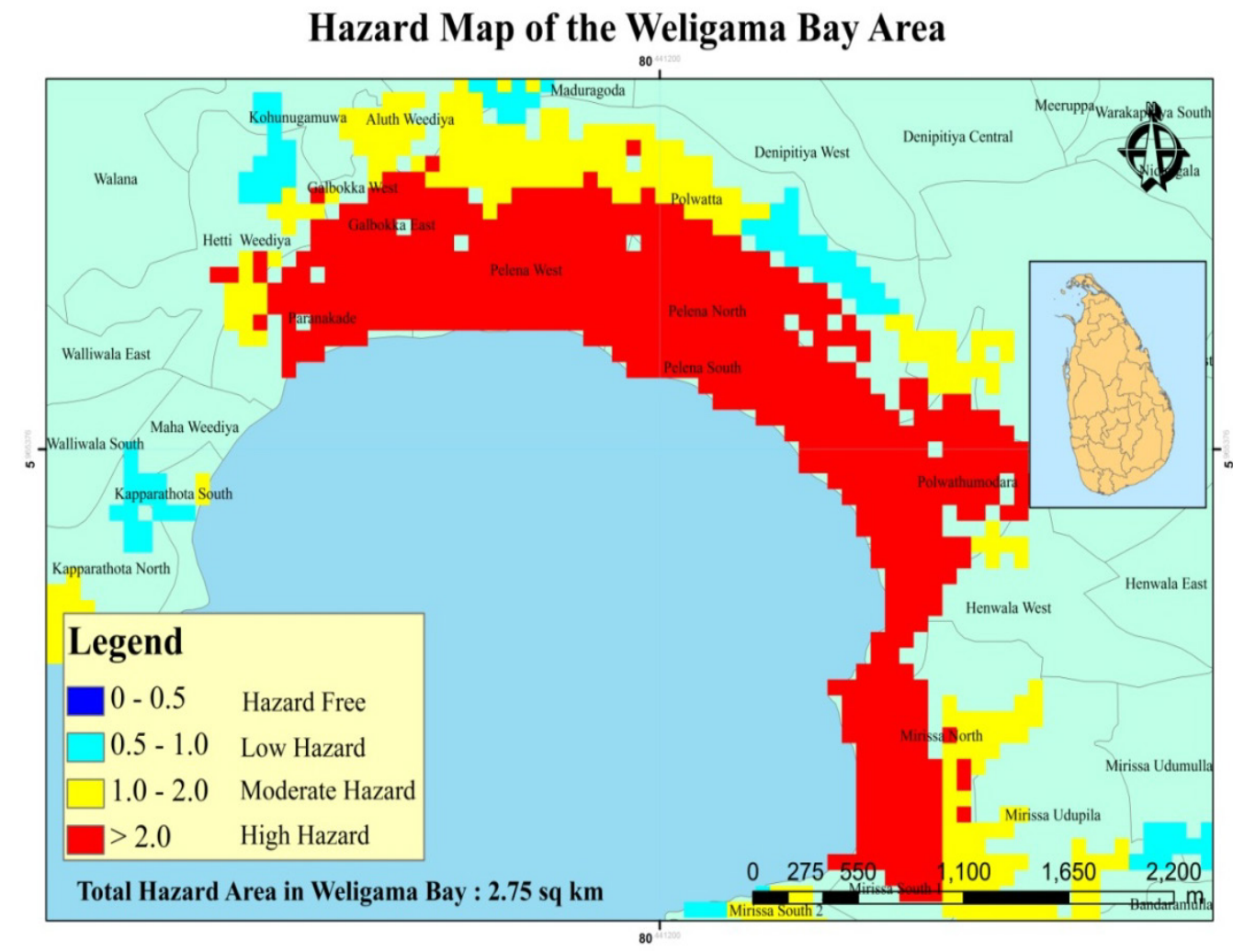

Figure 4. Tsunami Hazard Map in Weligama Bay Area 


\section{Results and Discussion}

The inundation depth is one of the most important parameters for analysing the level of damage due to tsunami. Figure 3 indicates the computed inundation depth distribution along the Weligama coastal belt and the tsunami wave height was estimated at 3-4 $\mathrm{m}$ along the coastline. In this study, the inundation depth, which is given by the model, was classified into four levels; $0-0.5 \mathrm{~m}, 0.5-1.0$ $\mathrm{m}, 1.0-2.0 \mathrm{~m}$ and greater than $2 \mathrm{~m}$, using the Arc GIS tool for identifying hazard zones. Figure 4 indicates the Tsunami hazard map in the Weligama Bay area.

Vulnerability is defined as the potential for damage while hazard, for a Tsunami event, is defined as the wave height. In order to examine the vulnerability in relation to land use and population density was used. Vulnerability maps recognize sectors within the selected areas that are highly vulnerable to a maximum tsunami run-up and flood event.

The inundation map integrates with land use based population density map of Weligama city to find the affected areas due to Tsunami. By using the weighted overlay method find out the risky areas in three stages like low, moderate and high risk ( Figure 5).

According to the results of the tsunami affect in 2004, it can be realized that the area which was identified as the risky by the tsunami modeling, was greatly affected and lost massive of lives and damaged to the property. Hence, Preparation of tsunami inundation maps is very important for delineation of evacuation routes and long term planning in vulnerable coastal communities and to provide early warnings to take precautions to protect from any kind of natural hazards.

The results show the high hazard zone covering a larger area of the Weligama Bay and the coastline. The Quick Birds Satellite image clearly shows the damaged areas in the Weligma Bay (Figure 06) and overlay analysis has given a clear representation to evaluate the results given by the ComMIT numerical model.

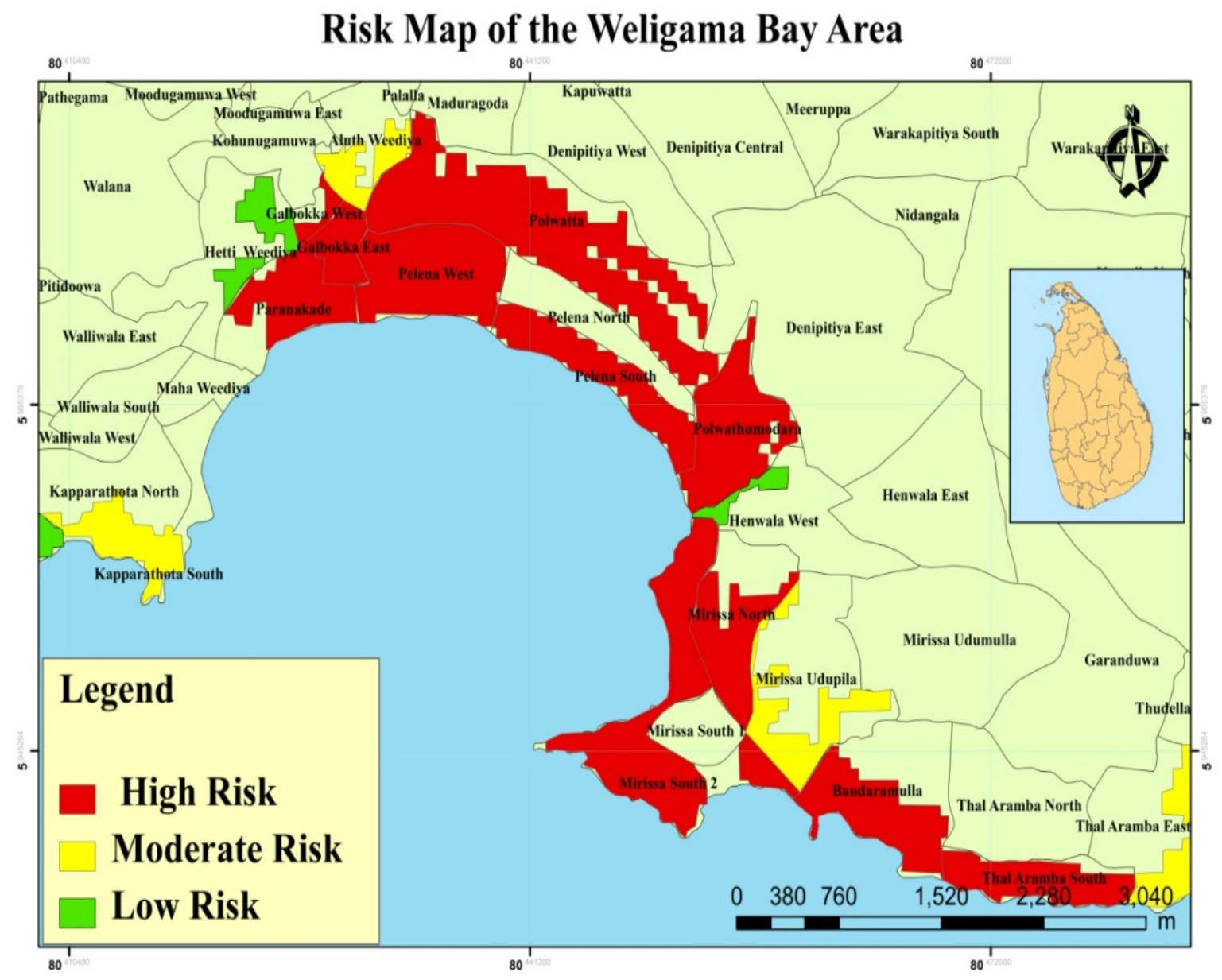

Figure 5. Risk Map 

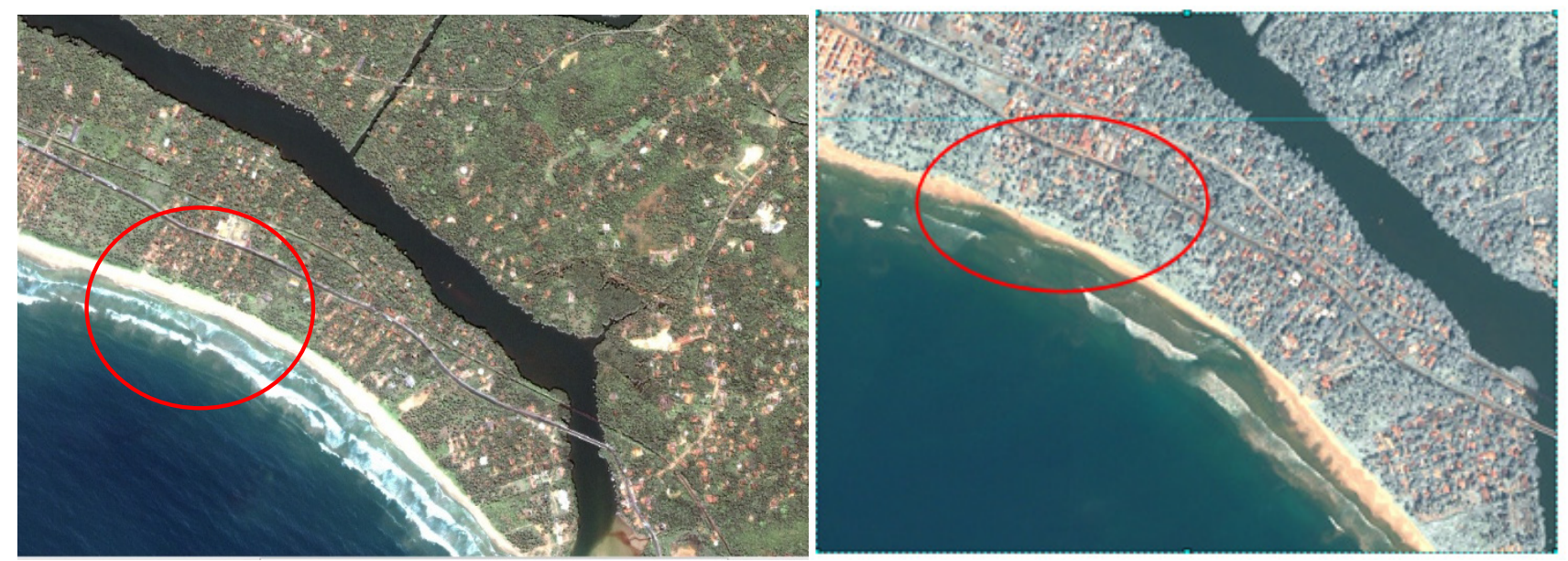

Figure 6. Tsunami Affected area in Weligama Bay

\section{Conclusions}

The Tsunami numerical model was used for the tsunami hazard assessment, incorporating high-resolution near-shore bathymetric and topographic data to model the 2004 tsunami event. The results shows that the areas in Weligma Bay are in a high tsunami hazard risk area due to its low elevation and topography. The validation of the model results with field surveyed data on the 2004 tsunami event shows an $80 \%$ match with the field observations. Accuracy of the Tsunami hazard prediction depends on the estimation of earthquake source parameters and accuracy of the DTM. Understanding vulnerability and hazard level, identification of possible mitigation measures, of the socio-economic impact caused by the event is very important to evaluate the level of the risk.

Tsunami risk assessment is performed in the study area incorporating tsunami hazard, population and land use vulnerability information. The risk map shows $97.61 \%$ of the study area falls in very high risk zone while $1.735 \%$ falls in moderate and the rest $0.65 \%$ falls in low hazard zone. The inundation modeling used for tsunami hazard assessment incorporates high resolution near shore bathymetry and LIDAR (Light Angle \& Detection Ranging) to model the December 2004 tsunami inundation even.

The study reveals that integration of remote sensing, GIS and demographic data with numerical inundation model is quite useful for tsunami risk assessment studies. GIS tools provide a scientific approach to the management of the possible disasters. The results output can be validating with the ground truth data to identify the reliability of the tsunami numerical model. The hazard map facilitates to decision makers to understand an evacuation planning \& in public education \& awareness activities \& provides indication to demarcate suitable sites for rehabilitation. Understanding vulnerability and hazard level, identification of possible mitigation measures, of the socio-economic impact caused by the event is very important to evaluate the level of the risk.

The evaluations of different type of geo data in a GIS environment allow the delineation of areas susceptible to tsunami flooding and inundating in the coastal areas. This study provide an important clue on variations in tsunami inundation along the Weligama coast reducing tsunami damages and planning mitigation measures in future which is mainly controlled by local geomorphologic set-up, coastal zone topography including natural barriers to protect coastal erosion and near shore bathymetry. This method is useful for tsunami risk assessment while the local authorities can use it for early warning and evocation purposes by creating different earthquake scenarios. The study could contribute in reducing tsunami damage and planning mitigation measures in future.

\section{REFERENCES}

[1] Borah R., Rajapaksha J., Hazarika M.K., Samarakoon L., 2007. Tsunami Risk Assesement of Galle City, Sri Lanka Integrating Numerical Model with Remote Sensing \& GIS Data. www.aars-acrs.org/acrs/proceeding/ACRS 2007/papers/TW2.1.pdf.

[2] Department of Census and Statistics, 2005. Preliminary Report on Census of Buildings and Persons Affected by the Tsunami -2004, Hambantota, Sri Lanka.

[3] Herath S., 2008. Post Tsunami Survey for Hazard Map Preparation in Sri Lanka. Environment \& Sustainable Development Programme, United Nations University, 5-53-70 Jingumae, Shibuya - ku, Tokyo 150-8925. www.wm.hq.unu.edu/tsunami survey/pages/documents/pdf/overview.pdf.

[4] Kumar C.S., Murugan P.A., Krishnamurthy R.R., Batvari B.P.D., Ramanamurthy M.V., Usha T., Pari Y., 2008. Inundation Mapping - A study based on December 2004 Tsunami Hazard along Chennai Coast, South East India. www.nat-hazards-earth.syst-sci.net/8/6/7../nhess-8-617-2008 .pdf.

[5] Imamura F., Gica E., Takahashi T., and Shuto N., 1995. Numerical simulation of the 1992 Flores tsunami: Interpretation of tsunami phenomena in northeastern Flores Island and damage at Babi Island. Pure Appl. Geophys. pp. 
$555-568$.

[6] Wilkinson C., Souter D. and Goldberg J., 2006. Status of Coral Reefs in Tsunami Affected Countries: 2005, Global Coral Reef Monitoring Network, Australian Institute of Marine Science.
[7] Willige B.T., 2006. Tsunami Hazard Assessment on the Northern Aegean Sea. Department of Berlin University of Technology, Hydrogeology \& Bureau of Applied Geo Scientific Remote Sensing, Germany. www.tsunamisocietyorg $/ 27 /$ willige.pdf. 